\title{
THE EFFECTS OF THE CARDIAC GLYCOSIDES UPON THE DYNAMICS OF THE CIRCULATION IN CONGESTIVE HEART FAILURE. I. OUABAIN ${ }^{1,2}$
}

\author{
BY RICHARD A. BLOOMFIELD, BERNARD RAPOPORT, J. PERVIS MILNOR, \\ WALTER K. LONG, ${ }^{3} \mathrm{~J}$. GILMER MEBANE, AND LAURENCE B. ELLIS \\ WITH THE TECHNICAL ASSISTANCE OF M. RITA LAVIN \\ (From the Thorndike Memorial Laboratory, Second and Fourth Medical Services [Harvard], \\ Boston City Hospital, and the Department of Medicine, Harvard Medical School, Boston)
}

(Received for publication December 22, 1947)

\section{INTRODUCTION}

While the clinical recognition, and even quantitative appraisal of congestive heart failure is a matter of routine in the practice of medicine, no precise definition of this state has been formulated which is equally satisfactory to clinicians, physiologists and pathologists. There seems little doubt that among the many aspects of the circulation which may be affected when cardiac function is abnormal, no single abnormality is always the major or primary factor, nor need any single one invariably be present. This is true for changes in cardiac output, blood volume, sodium retention, diastolic heart volume, mechanical efficiency of the heart, peripheral venous pressure, intracardiac pressures, and peripheral vasomotor reactions. It is nevertheless true that clinically the diagnosis of heart failure is made by the detection of signs and symptoms referable to abnormal increases in the volume of blood in various parts of the circulation-and the assumption is made that these increases are the result of aberration in cardiac function.

Equally a matter of routine in clinical medicine is the administration of a cardiac glycoside, either in a relatively pure state or more often as digitalis leaf, in the justified expectancy that it will serve to help dispel and prevent recurrence of congestive heart failure. Yet, in spite of a voluminous literature upon the subject, there is still great diversity of opinion as to the site and mode of action of these drugs upon the circulation, especially in human beings, and as to differences among the individual drugs in these actions.

1 The expenses of this investigation were supported by a grant from the Life Insurance Medical Research Fund.

2 Read at the Meeting of the American Society for Clinical Investigation, Atlantic City, May 5, 1947.

8 Post-graduate Research Fellow, Life Insurance Medical Research Fund.
The object of the present study is twofold: first, by the application of certain newer techniques, to gain further insight into the action of various cardiac glycosides in patients with congestive heart failure; second, to gain information as to causal relationships between the various circulatory abnormalities, from a study of the emergence of patients from congestive failure.

Thirteen patients with heart disease, with and without clinical evidence of congestive failure, were chosen who had not received any cardiac glycoside within three weeks. The one exception to this was Patient No. 12, who was given $0.6 \mathrm{mg}$. of ouabain 12 hours before the control observations reported. Most of them were studied within 12 to 24 hours after admission to the hospital. Therapy had consisted of rest, sedation and occasionally oxygen. Patients were studied fasting, and wherever compatible with their comfort, in the recumbent position. While circumstances were often not conducive to a truly basal state, a preliminary oxygen consumption was done under conditions of quiet, for purposes of comparison with later determinations. Catheterization of the right heart was performed with a single-lumen catheter, using the method of Cournand and Ranges (1-3), and the catheter was guided into the right ventricle or pulmonary artery under fluoroscopic visualization.4 In one case, auricular catheterization only was possible. An inlying needle was placed in one femoral artery, and in nine patients in a peripheral arm vein. Electrocardiographic leads were attached in all cases. The catheter was kept patent by a slow, continuous drip of a 5 per cent solution of glucose in distilled water, to $1500 \mathrm{cc}$. of which $5 \mathrm{mg}$. of heparin was added. Cardiac outputs were done by the direct Fick method. Mixed venous blood samples were taken from the right ventricle except in Patient No. 7 where an auricular sample was used; blood oxygen contents were measured by the Van Slyke technique. Oxygen consumption during the blood sampling was determined graphically on a metabolism machine, using two- to fourminute breathing periods as the basis for computing the minute uptake. Intracardiac, femoral arterial and peripheral venous pressures were optically recorded through

4 Assistance in fluoroscopic visualization was given by the X-ray Department (Dr. Max Ritvo, Director). 
Hamilton manometers. The zero level for pressures in the peripheral vein and lesser circuit was taken as $5 \mathrm{~cm}$. below the angle of Louis. Femoral systolic and diastolic pressures were obtained by averaging the measured values of a representative sequence of beats in one or more respiratory cycles. Right ventricular systolic and pulmonary arterial systolic and diastolic pressures were similarly averaged. Femoral mean, pulmonary mean, right auricular and peripheral venous pressures were measured by planimetric integration. The diastolic pressure in the right ventricle was measured at the moment of onset of the systolic rise, since this figure was held to be most representative of the filling pressure at which systole began (4), and hence of the tension within the ventricular myocardium at its beginning of contraction. Pulse pressures in the femoral and pulmonary arteries were measured as the difference between the systolic and diastolic values. The right ventricular pulse pressure was measured as the difference between the systolic and the end-diastolic pressures. The peripheral arterial resistance was computed in accordance with the formula:

- $\quad R=\frac{\left.P_{m} \text { (mean pressure in } \mathrm{mm} . \mathrm{Hg}\right) \times 1332}{\text { C.O. (cardiac output in } \mathrm{cc} . / \mathrm{sec} .)}$
(5)
Sterile solutions of ouabain were injected through the catheter over a period of one to two minutes in doses of 0.25 to $0.75 \mathrm{mg}$.

In nine patients, a cardiac output was done before giving ouabain, and at the end of the observation period, which varied from about 40 to about 160 minutes. In one patient studied early in the series, before it was realized how quickly significant data could be obtained, both outputs were done after the administration of ouabain. In three patients (Nos. 11, 12,13), in addition to a control, serial cardiac outputs were done after they had received the drug, at the times noted on the charts. In each instance pressures were recorded as close to the time of the outputs as possible and at varying intervals between.

\section{CASE MATERIAL}

Thirteen patients were studied. The diagnoses and clinical state of compensation are listed below.

(a) In clinical congestive failure-10 Arteriosclerotic heart disease Hypertensive heart disease Hypertensive and arteriosclerotic heart disease Cor pulmonale

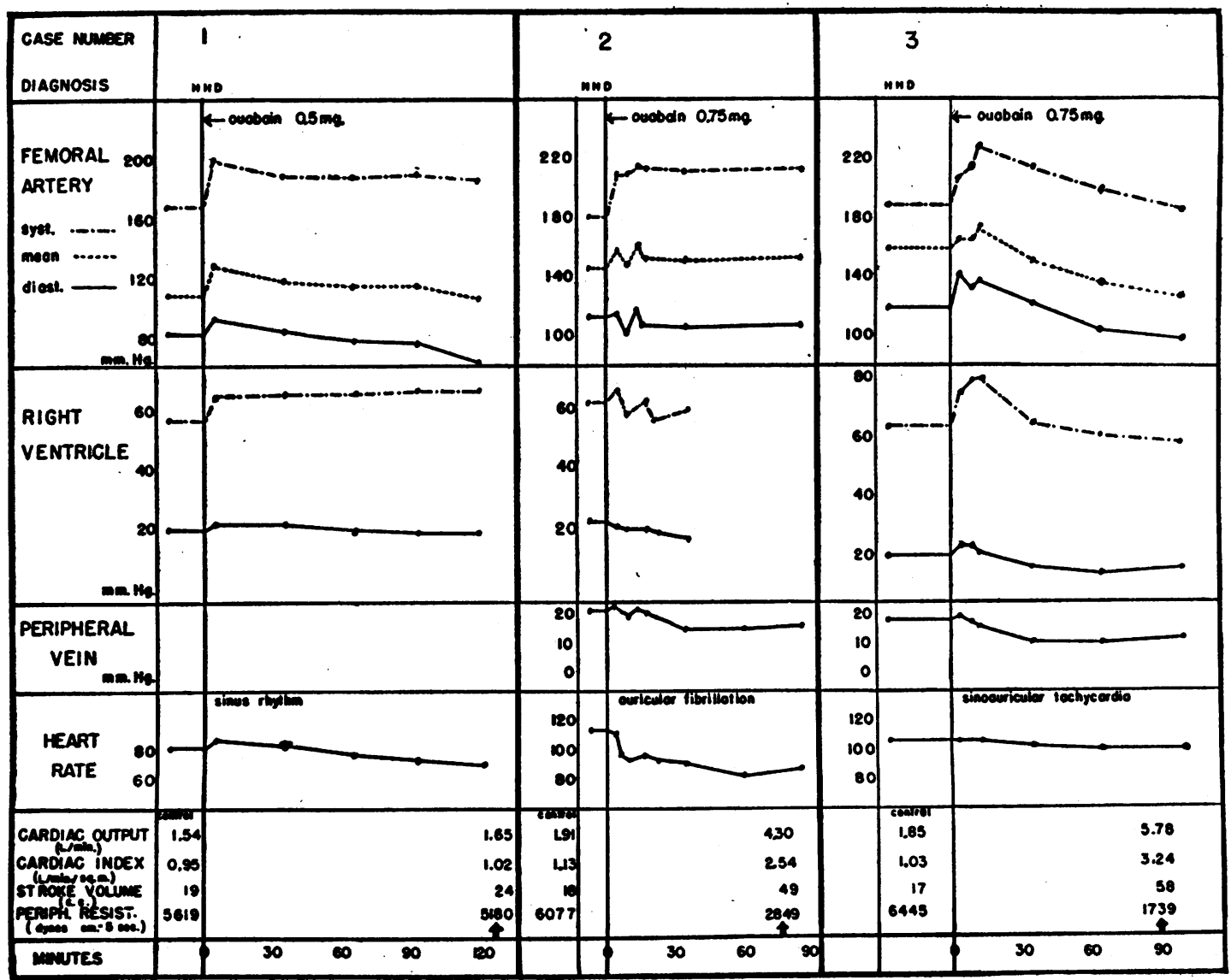

Fig. 1. Three Patients with Hypertensive Heart Disease in Clinical Heart Failure, with InCrease in Cardiac OUtputs after OUabain 
(b) Not clearly in clinical congestive failure-3

Arteriosclerotic heart disease

Rheumatic heart disease with mitral stenosis

Heart disease of unknown etiology, ? beriberi

Four of the patients in Group (a) and two of those in Group (b) had auricular fibrillation.

\section{RESULTS}

Cardiac output. An increase in cardiac output was noted in ten patients, including nine of those in obvious congestive failure. A decrease in output was observed in two patients, neither of whom was in clinical failure. No significant change took place in one patient who was in heart failure.

Pressure changes. Significant pressure changes following ouabain were noted within one to eight minutes in ten of the 12 studies in which control data were obtained prior to the drug's administration. One exception was Patient No. 7 who received the small dose of $0.25 \mathrm{mg}$. At five minutes his pressures were unchanged; the next observations were made at 35 minutes. The other exception was Patient No. 10 whose first postouabain measurements were not made until 27 minutes, at which time changes were present. In Patient No. 8 the first measurements were made 46 minutes after ouabain was given; at the time of the next observation-27 minutes later-the changes shown on his chart were found.

The multiplicity of changes which had occurred by the end of the experimental period made it ap-

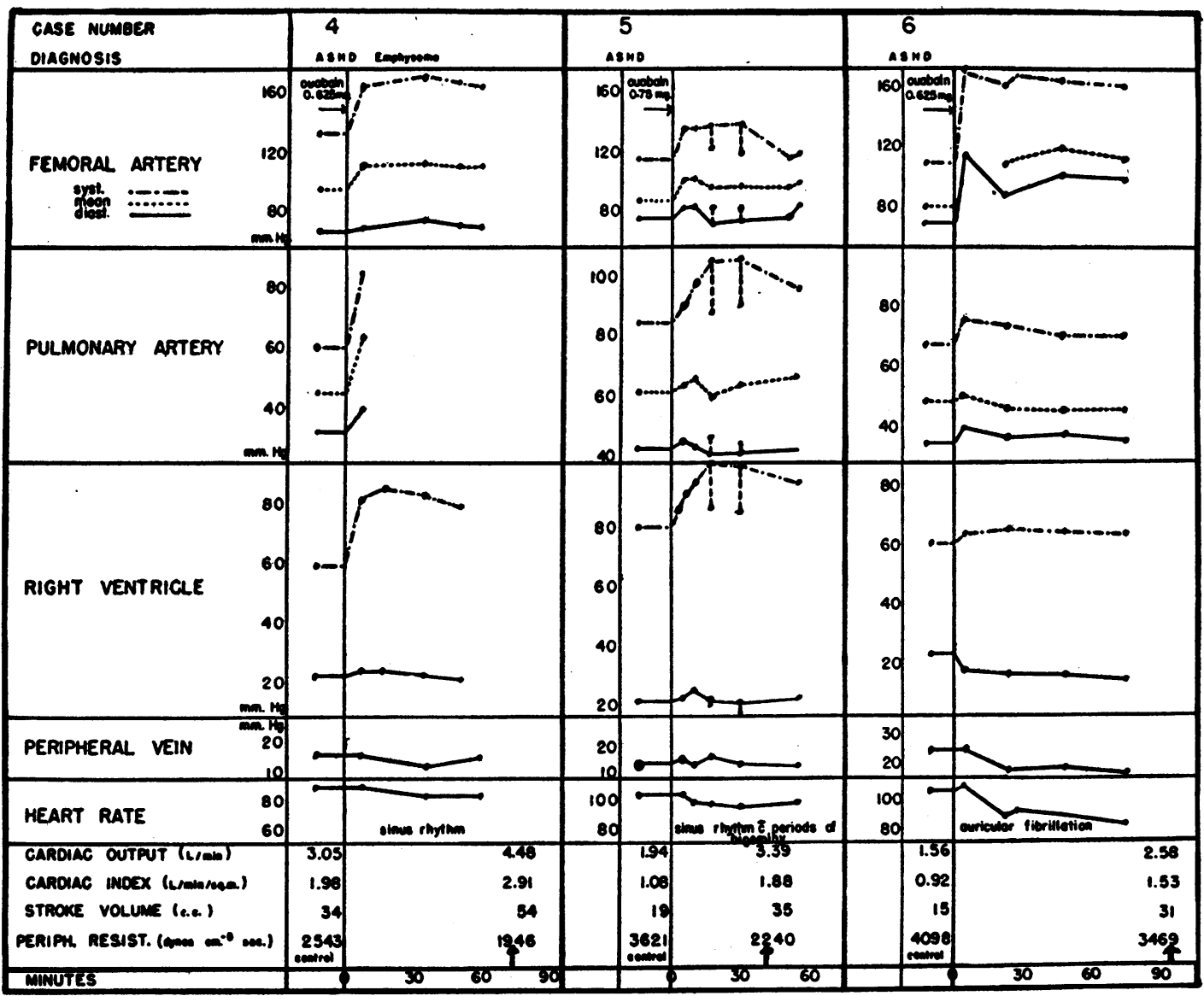

Fig. 2. Three Patients with Arteriosglerotic Heart Disease in Cinical Heart Failure, with InCREase in Cardiac Outputs after Ouabain

In Case No. 5 during periods of bigeminy the pressures of ectopic beats are charted separately and connected to the pressures of normal beats by vertical broken lines. In Case No. 6 the discrepancy between pulmonary arterial and right ventricular systolic pressures was due to oscillatory artefacts which rendered inexact the measurement of the point of maximum pressure. 


\begin{tabular}{|c|c|c|}
\hline $\begin{array}{l}\text { CASE NUMBER } \\
\text { DIAGNOSIS }\end{array}$ & & $\begin{array}{c}7 \\
\text { HHD : ASHD }\end{array}$ \\
\hline $\begin{array}{l}\text { FEMORAL } \\
\text { ARTERY } \\
\text { sys. } \\
\text { moon . } \\
\text { miost. }\end{array}$ & $\begin{array}{c}180 \\
140 \\
100 \\
\mathrm{mmH}\end{array}$ & oubbain $0.25 \mathrm{mg}$ \\
\hline $\begin{array}{l}\text { RIGHT } \\
\text { AURICLE }\end{array}$ & \begin{tabular}{r|}
20 \\
10 \\
m.
\end{tabular} & \\
\hline HEART RATE & $\begin{array}{r}100 \\
80\end{array}$ & sinus rmythm \\
\hline$\underset{\substack{\text { CL/mila }) \\
\text { CARDIAC OUTPUT }}}{\text { and }}$ & 6.00 & 7.67 \\
\hline $\begin{array}{c}\text { CARDIAC INDEX } \\
(\text { L/min/som) }\end{array}$ & 2.72 & 348 \\
\hline $\begin{array}{c}\text { STROKE VOLUME } \\
\text { ( e.c.) }\end{array}$ & 68 & 86 \\
\hline 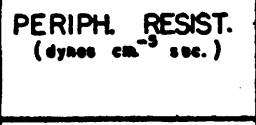 & $\begin{array}{l}1612 \\
\text { control }\end{array}$ & $\stackrel{1394}{\uparrow}$ \\
\hline MINUTES & & $30 \quad 60$ \\
\hline
\end{tabular}

Fig. 3. Patient with Hypertensive and Arteriosclerotic Heart Disease in Clinical Heart Failure, with Increase in Cardiac Output after Ouabain

parent that the site and mode of action of ouabain could only be seen from the actual sequence in which such changes developed. For purposes of clarity the complete data from each case are shown graphically.

\section{A. Early changes.}

I. In the course of a rising cardiac output.

(a) Patients in clinical congestive failure: A striking uniformity of response can be seen in the nine patients who were in failure (Nos. 1-7; $11,12)$. All initially showed elevations of pressure in the right heart and pressure pulse contours of a type previously reported as found in right heart failure (4). In every instance following ouabain, femoral arterial systolic pressures promptly rose as did the mean and pulse pressures; this occurred, however, considerably later in Patient No. 7 who received the smallest dose. In the eight on whom records were taken, right ventricular systolic and pulse pressures also increased (Nos. $1-6 ; 11,12$ ). In Patient No. 6 technical difficulty made impossible the measurement of femoral mean pressure at the time the other earliest changes were seen; at the time of the next observations, the femoral mean pressure was found to have risen markedly. In the three instances in which it was possible also to measure pulmonary arterial pressures both systolic and pulse pressures were similarly increased (Nos. 4 6; Figure 8). While ventricular diastolic pressures varied in degree of response, a significant drop was noted only in the ventricular diastolic pressure of Patient No. 6; here, too, however, the increased pulse pressure was accompanied by an increased systolic pressure. In the seven cases with recorded peripheral venous pressures no sig- 
nificant change was seen up to the time at which these other phenomena had become apparent (Nos. $2-6 ; 11,12)$. In the two patients lacking peripheral venous pressure data, the auricular pressure was unchanged in one (No. 7), while the ventricular diastolic pressure actually rose slightly in the other (No. 1). At the time that pressure changes already were manifest, the heart rate had not altered in five patients (Nos. 3-5; 7, 12); in two, the rate had risen by four beats per minute (Nos. $1,6)$, and one of these had auricular fibrillation. The other two patients with auricular fibrillation exhibited a decline in ventricular rate from 114 to 97 in the first six minutes in Patient No. 2, and from 140 to 130 in three minutes in Patient No. 11. (b) Patients not in clinical congestive failure: In the one patient not clearly in heart failure in whom the cardiac output rose (No. 8), the only significant change was a decline of $5 \mathrm{~mm}$. $\mathrm{Hg}$ in the initially normal ventricular systolic pressure.

\section{In the course of a falling cardiac output.}

Patient No. 10 showed a small diminution in femoral systolic and diastolic pressures, with a slight decrease in the pulse pressure; the right ventricular pulse pressure widened by $4 \mathrm{~mm}$., as a result of a slight rise in the systolic and a slight fall in the diastolic pressures. The fall in output was due almost wholly to a drop in heart rate, as

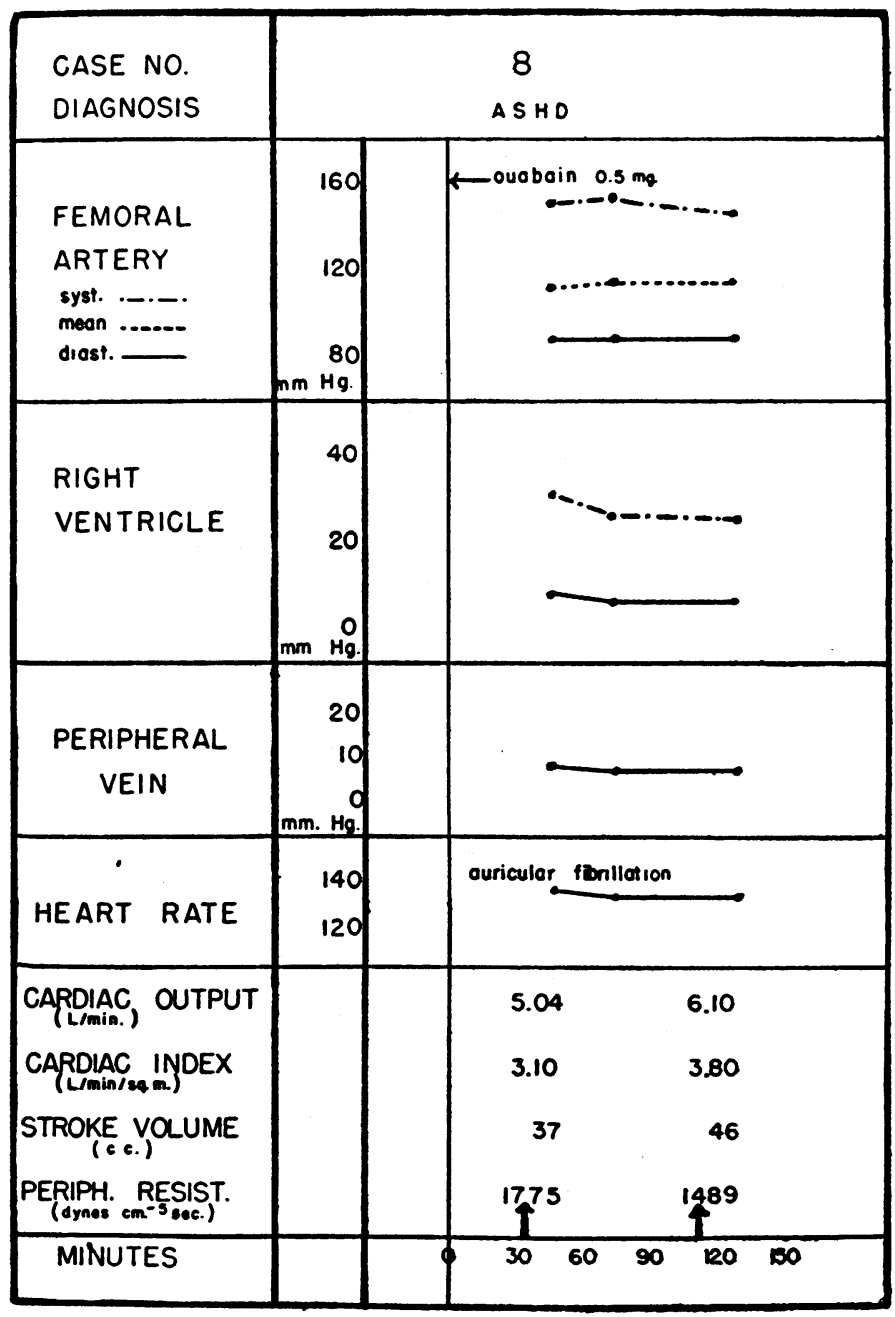

Fig. 4. Patient with Arteriosclerotic Heart Disease not in Clinical Heart Failure, with Increase in Cardiac OUtPUT AFTER OUABAIN 


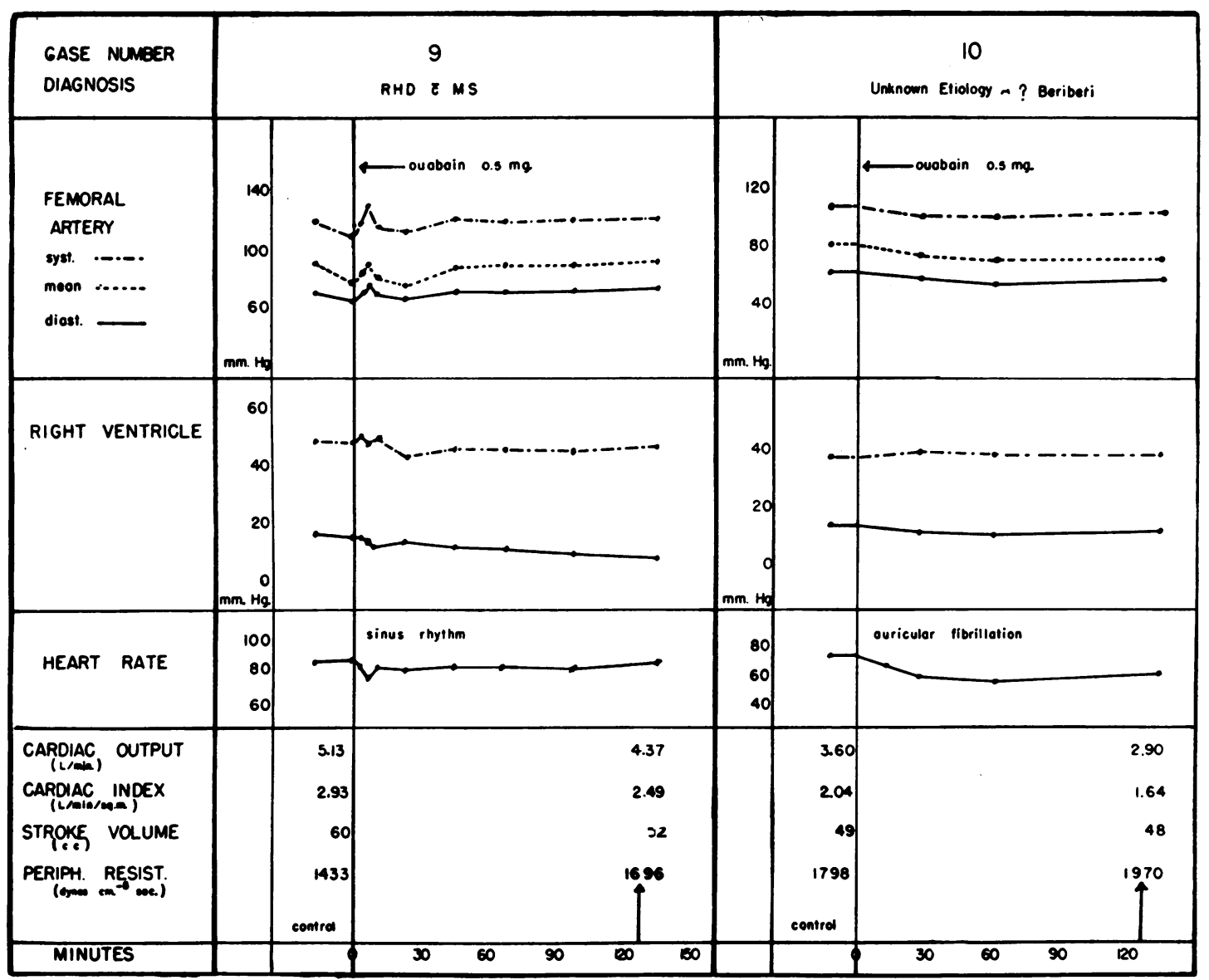

Fig. 5. Two Patients not in Clinical. Heart Faillere, With Decrease in Carmic Oltplots AFTER OUABAIN

seen by the stroke volume which changed by only 1 cc., from 49 to 48 .

The second patient whose output fell (No. 9) showed a definite early increase in femoral systolic and diastolic pressures, with a moderate increase in the pulse pressure; the right ventricular pulse pressure rose $4 \mathrm{~mm}$.. as a result chiefly of the fall in diastolic pressure. At this time his heart rate had decreased by 13 beats per minute.

In neither case was the peripheral venous pressure measured.

III. In the absence of a change in cardiac output.

In Patient No. 13 the changes in cardiac output were of an order so small that no action of ouabain can be held accountable for them. Five minutes after the drug was given the femoral systolic, diastolic and mean pressures had all risen to the same degree, with no resulting alteration in pulse pressure. At ten minutes these values showed a decline toward control levels. During this interval the ventricular systolic and diastolic, and peripheral venous pressures, as well as the heart rate, were essentially unaltered.

\section{B. Later changes.}

As seen in the figures there was considerable variation in the degree to which the early changes described were maintained over the remainder of the experiments.

Of the nine patients in congestive failure showing rises in cardiac output, seven maintained a femoral systolic pressure increase (Nos. 1, 2, 4, $6,7,11,12)$, while two returned to approximately control levels (Nos. 3, 5). Three maintained their early diastolic arterial pressure rise (Nos. 5-7). Only one, however, failed to keep an in- 
creased arterial pulse pressure (No. 5). Five of the eight patients with ventricular pressure records maintained their early systolic increase (Nos. $1 ; 4$ $6 ; 12)$; only four showed a significant fall in diastolic pressure (Nos. 2, 3, 6, 11); all but two (Nos. 3, 11) maintained a widened ventricular pulse pressure. Only two of the pulmonary artery studies were followed throughout the experiment (Nos. 5, 6). In both the initial increase in pulse pressure was present to the end; in one the early slight diastolic pressure rise was followed by a fall to the control value. The peripheral venous pressure fell in five cases (Nos. 2, 3, 6, 11, 12). In four also, there was a decline in heart rate by the conclusion of the observations (Nos. 1, 2, 6, 11). No change occurred in the auricular pressure in Patient No. 7.

In the patient not clinically in heart failure (No. 8), but whose cardiac output rose, no further important change was noted in any of the subsequent measurements.

The patient with mitral stenosis and a fall in cardiac output (No. 9) showed a return to the range of his control values except for a continued decline of ventricular diastolic pressure. The other patient whose cardiac output dropped (No. 10) showed no significant further changes after the early ones described, except a continuing moderate fall in heart rate. In the patient (No. 13) whose cardiac output showed little variation there was a gradual return of femoral pressures to their control level. The other data showed no appreciable variation throughout the experiment.

\section{DISCUSSION}

Numerous articles have been published on the physiological and pharmacological effects of ouabain (6-9) as well as of the other cardiac glyco-

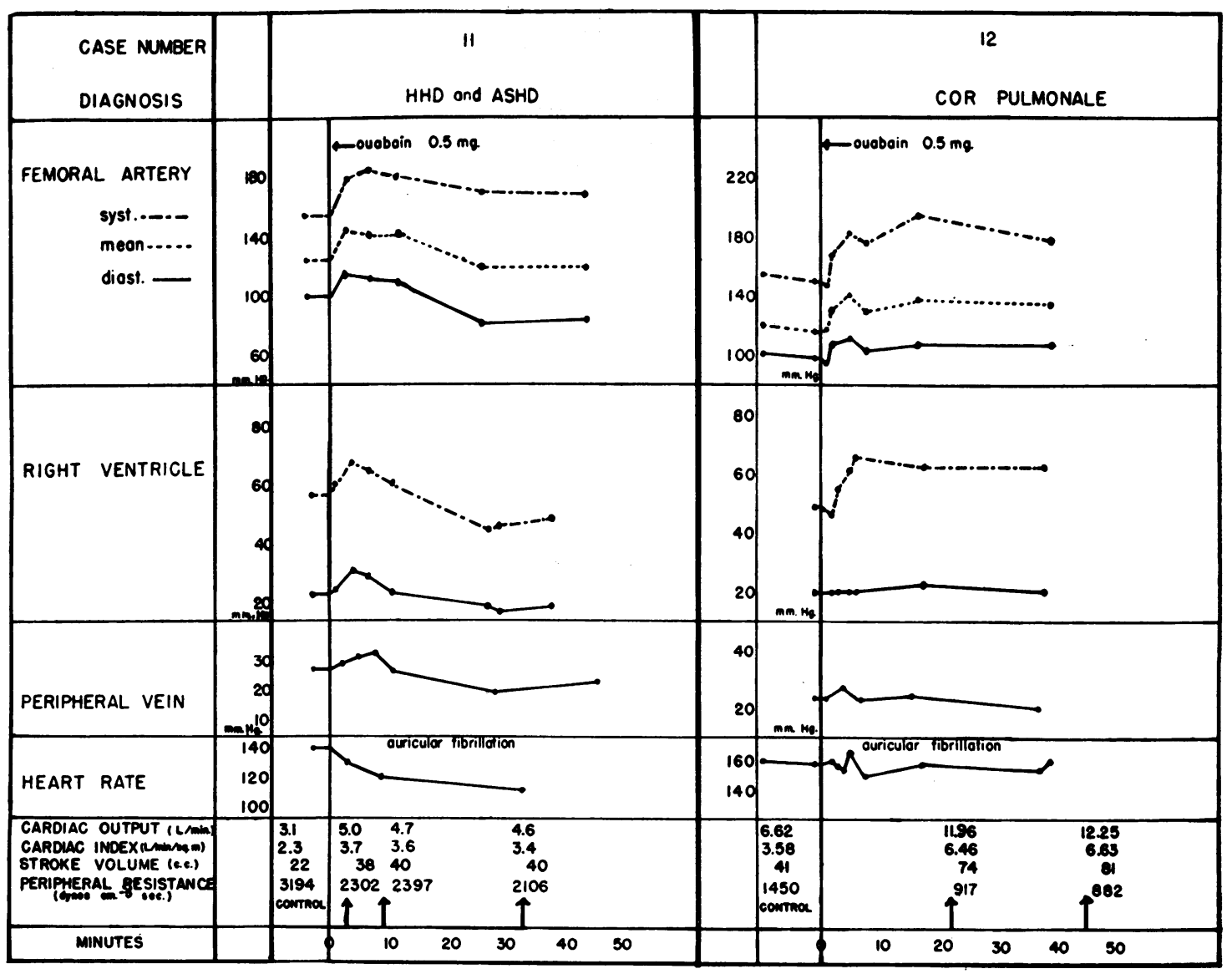

Fig. 6. Two Patients in Clinical Heart Failure

Serial determinations show increases in cardiac outputs after ouabain. 


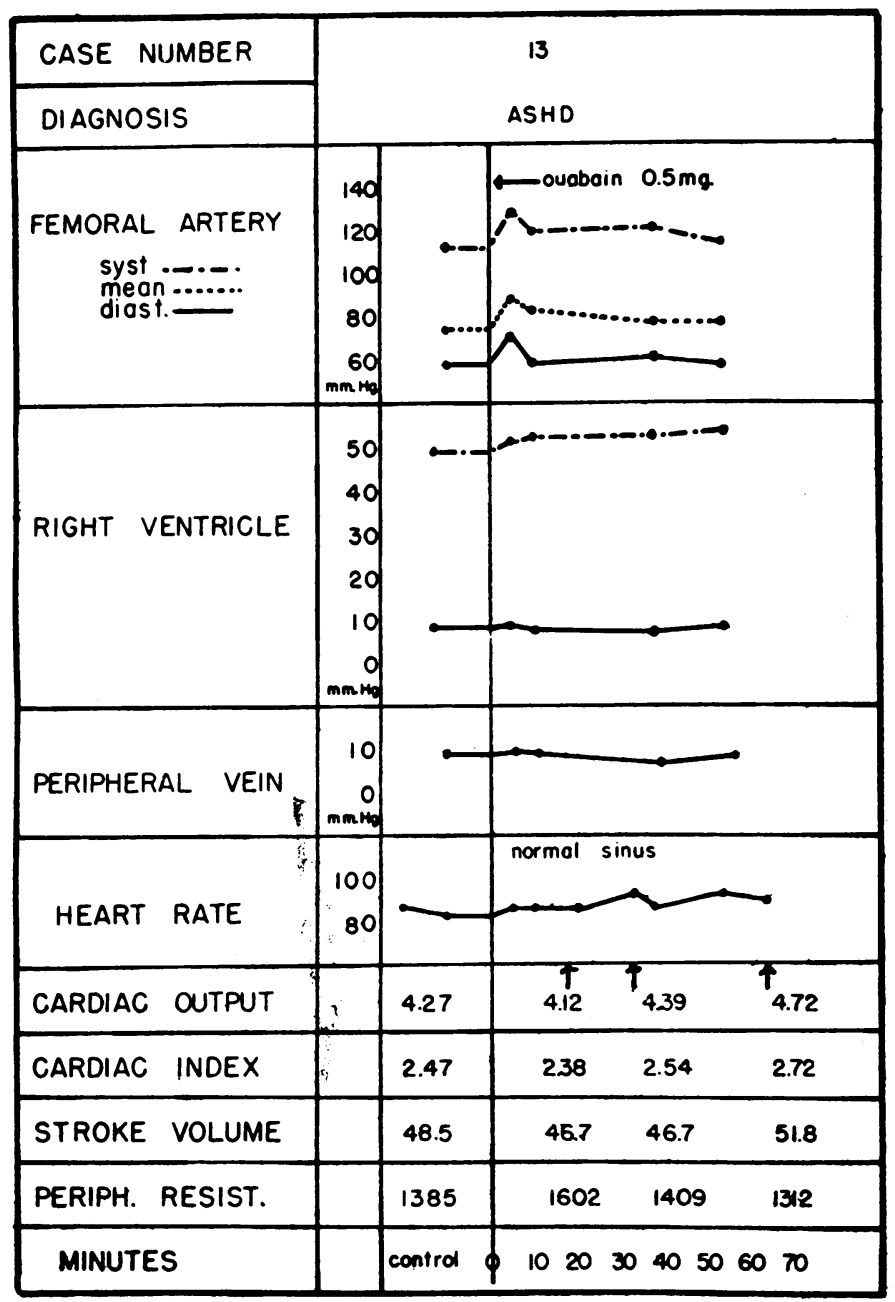

Fig. 7. Patient with Arteriosclerotic Heart Disease in Clinical Heart Failure

Serial determinations show no definite effect of ouabain on cardiac output.

sides. Summaries have been recently published by Freedberg and Zoll (10) as well as in the monograph by Movitt (11). In general it is believed that ouabain has an action on the circulation that is qualitatively similar to that of the digitalis glycosides and that the chief quantitative differences in its behavior are its rapidity of action, its rapid elimination, and its failure of absorption by the gastro-intestinal tract. It is the opinion (12) of some physiologists and clinicians, especially of the European and Latin American schools, that ouabain also differs from digitalis in having relatively less effect on the sinus node and junctional tissues but a more effective action on the cardiac musculature itself.
The pattern of early response in the nine patients in heart failure who exhibited a rise in cardiac output was so consistent that an identical effect of ouabain is suggested in them all. Their resting cardiac outputs were below normal, as shown by cardiac indices varying from 0.92 to $2.72 \mathrm{~L} / \mathrm{min}$./sq. m.. with the exception of $\mathrm{Pa}$ tient No. 12 whose higher figure is consistent with his diagnosis of cor pulmonale $(13,14) .^{5}$ As seen from the data, the stroke volume rose in each instance under the influence of ouabain. That a decrease in filling. and hence a decrease in diastolic stretch "from behind," from the pe-

5 The average normal cardiac index is considered to be $3.12 \pm .40 \mathrm{~L} / \mathrm{min} . / \mathrm{sq} . \mathrm{m}$. $(3.15)$. 
ripheral venous pressure head, did not account for this stroke volume change seems established by the fact that the peripheral venous pressure had not decreased at the time of the first demonstrated increase in cardiac output in four of the seven subjects in which it was measured. In the two patients in whom this phenomenon was not studied, an equally valid index to ventricular filling was seen in the unchanged auricular pressure of Patient No. 7, and in the ventricular diastolic pressure of patient No. 1. In the three patients in whom the venous pressure had decreased at the time of the post-ouabain cardiac output determination, no change in this measurement had occurred earlier at a time when other marked circu- latory effects were already evident in vascular pressure changes.

An effect on stroke volume and cardiac output through an action of ouabain on the ventricular rate seems poorly borne out by the lack of correlated change in seven instances; in Patient No. 11 where the rate had fallen at the time of the first measured rise in output it is noteworthy that the subsequent decline in rate was of the same order, but with a slight drop in output and no change in stroke volume. The only other mechanism, therefore, that can plausibly explain the increased stroke volume, is an increase in the vigor of ventricular systole as a result of the direct action of ouabain upon the contractility of the

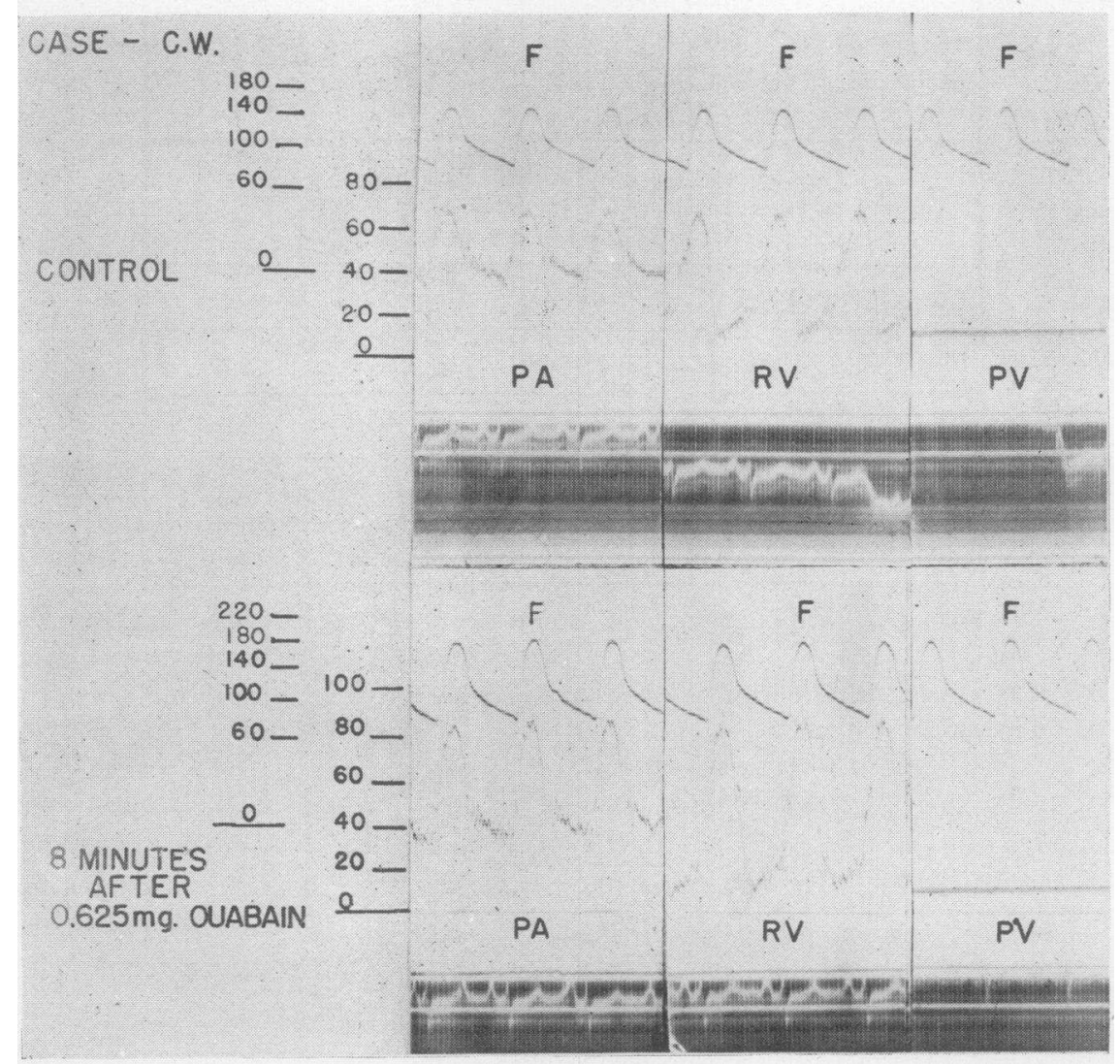

Fig. 8. Tracings of Case No. 4

The upper group shows control observations: simultaneous femoral arterial (F) and pulmonary arterial (PA) pressures; femoral arterial (F) and right ventricular (RV) pressures; and femoral arterial (F) and peripheral venous (PV) pressures. A simultaneous electrocardiogram is recorded in the lower part of each series. The pressure scales are in $\mathrm{mm}$. of mercury, one for the femoral artery, one for the right heart and venous pressures. The two latter were done with the same manometer and from the same zero. The lower group shows corresponding tracings eight minutes after ouabain with the changes in pressures readily seen. 
myocardium. The early pulse pressure changes are consistent with such a mechanism, and would indicate that it occurs very promptly after injection of ouabain. While changes in the peripheral resistance at this time, at both pulmonary and systemic arterioles, cannot be wholly excluded in those patients lacking early output studies after ouabain, the observed pressure changes are precisely what would be expected in the presence of a rapid and significant increase in cardiac output. In Patient No. 11 an increase in stroke volume and decrease in peripheral resistance were demonstrable within three minutes after the administration of ouabain at a time when the heart rate had fallen only from 140 to 130 , and the increase in stroke volume was maintained at two further observations. In Patient No. 12, in whom the heart rate did not change, the increase in cardiac output and decrease in peripheral resistance observed at 19 minutes after giving ouabain were maintained at 45 minutes. The predominant role of the systolic component in the pulse pressure increase speaks, furthermore, chiefly for a stroke volume change, rather than for a change in peripheral resistance. Moreover, were the pressure rises due mainly to an increase in peripheral resistance, one would expect not only a more uniform finding of increased diastolic pressure, but also, in these already decompensated hearts, still further evidence of failure in the form of an increasing venous pressure and a decreasing cardiac output. The variability of the later findings, in which in some instances a return of pressures toward the control level occurred, does not argue against such an interpretation, in view of the likelihood that ultimately such other factors must come into play as changes in blood volume, heart rate, blood viscosity, etc. It is of interest, and indeed in keeping with the proposed explanation, that in every case in this group, regardless of the absolute values of the final measured pressures, the peripheral resistance was below its initial figure.

In Patient No. 8, who was not clearly in heart failure, the output increased between 32 and 110 minutes after ouabain administration. It is possible that earlier changes occurred, which took place before the observations were made. The patient was of particular interest for his unchanging ventricular rate of 133 , in the presence of auricular fibrillation. While his initial right ven- tricular systolic pressure was normal, the peripheral venous pressure was in the upper normal range, and the normal gradient between the venous and ventricular diastolic pressures did not exista finding which, as Richards et al. $(16,17)$ have pointed out, may have the same significance in early right heart failure as a heightened venous pressure. In view, then, of his unaltered ventricular rate, and unaltered venous pressure, it is reasonable to suppose that the decline in ventricular pressures, chiefly systolic, resulted from the transfer of blood from the pulmonary field to the systemic side; and that there was prompt adjustment to this increased systemic arterial input by a lowering of the peripheral resistance. This would account for the absence in this case of the systemic arterial pressure rise seen in the patients with congestive heart failure, in whom later peripheral resistance fall seems to come only after adequate improvement of arterial filling.

The two patients whose cardiac outputs decreased (Nos. 9, 10) were not in heart failure by the usual criteria. Patient No. 10, however, had previously been in failure on several occasions, with heart disease of uncertain etiology. At the time of the present study, both right ventricular systolic and diastolic pressures were slightly elevated; the cardiac index was definitely low. The decline of his ventricular rate from 73 to 60 , while not striking, actually represents a stroke volume change only from 49 to $48 \mathrm{cc}$., so that the decline in cardiac output must here be ascribed almost wholly to the fall in rate, with a failure of ouabain in this case to affect ventricular systole. The slight drop in systemic pressures would be compatible with this decrease in arterial inflow from the left heart.

Patient No. 9 was suffering from rheumatic heart disease with mitral stenosis, not clinically in heart failure; he was able to work as a longshoreman until admission for study. His only symptom was cough. It will be seen that his cardiac index was also in the lower normal region, and that his ventricular diastolic pressure of 16 $\mathrm{mm} . \mathrm{Hg}$ was of the order seen in right heart failure. While there was some fall in heart rate between the two outputs, the rates at the time of blood sampling were 81 and 84 , respectively. The stroke volume decreased from $60 \mathrm{cc}$. to $52 \mathrm{cc}$. The early rise in systemic pressures was not sus- 
tained, final values being essentially the same as his controls. There was, however, a progressive fall in ventricular diastolic pressure to $8 \mathrm{~mm}$. In view of the nearly 20 per cent increase in peripheral arteriolar resistance, the decline in ventricular filling pressure may simply have represented a diminution of the venous return, as a consequence of decreased arteriolar outflow. The lesion in this instance was not comparable to those present in the other cases, and the action of ouabain, particularly upon a presumably normal left ventricle, was likewise not comparable. Further studies on the effects of ouabain in mitral stenosis are now in progress.

In Patient No. 13, who was in heart failure, the slight variation in all pressures except those in the femoral artery at five minutes after ouabain was consistent with the fact that there was but small variation in the cardiac output and stroke volume. The equal and brief rise in femoral systolic, diastolic and mean pressures five minutes after the drug was given suggests a transitory vasopressor response in this instance. However, the failure to obtain a closer time correspondence between the taking of control pressures and output on the one hand, and the follow-up pressures and outputs on the other, leaves interpretation of this early systemic response at best uncertain. This was the only patient in the series in whom, at the end of the observation period, no clear effect of ouabain upon the circulation was apparent.

The present study confirms in human beings with congestive heart failure the physiological effects of ouabain described in experimental animals as well as those reported in patients by less exact clinical measurements. Ouabain acts directly on the failing heart by increasing its stroke output, and this action may and usually does precede cardiac slowing or any decrease in peripheral venous or right ventricular filling pressure. The latter effects usually do take place, but later. Our results with ouabain are at variance with those reported by McMichael and SharpeyShafer $^{\circ}$ (18) with digoxin, in that they ascribed

- It should be pointed out that McMichael and SharpeyShafer imply peripheral venous pressure alterations, although measuring only central (auricular) pressures. Hemodynamically the two may not be regarded as synonymous. the improvement in cardiac output to a fall in right auricular pressure, and in our cases evidence for an improvement in cardiac output preceded any fall in venous pressure. Further studies are now in progress in this laboratory with digoxin as well as other digitalis glycosides.

\section{SUMMARY}

1. The intracardiac administration of ouabain in doses of 0.25 to $0.75 \mathrm{mg}$. to patients in clinical congestive heart failure, suffering from non-valvular types of heart disease, is usually followed by a rise in cardiac output, as seen in nine out of ten patients in heart failure in the present study.

2. Effects on the circulation may be noted within one to eight minutes, and are characterized by an increase in the systemic systolic and pulse pressures and in the right ventricular systolic and pulse pressures. There is a less marked and less uniform early change in the diastolic pressures in these two systems. Where measured, increases in the pulmonary arterial systolic and pulse pressures have also been seen.

3. There is a variability in the later pressure findings, at the end of one to two hours, which may be accounted for by the additional play of other factors such as changes in blood volume and peripheral arteriolar resistance.

4. While there may ultimately be seen evidence of diminished filling pressure in the right ventricle, measurement of the peripheral venous, auricular or ventricular diastolic pressure shows these values to be essentially unchanged at the time of the other pressure rises.

5. The increase in cardiac output is due to an increase in stroke volume.

6. The increased stroke volume can best be explained by a direct action of ouabain upon the contractility of the myocardium.

7. The systemic and right heart pressure changes described are consistent with such an explanation, although vasopressor effects of the drug are not entirely excluded.

8. In three patients the cardiac output was unchanged or fell after ouabain administration. Two of these patients were not in clinical heart failure. 


\section{BIBLIOGRAPHY}

1. Cournand, A., and Ranges, H. A., Catheterization of the right auricle in man. Proc. Soc. Exper. Biol. \& Med., 1941, 46, 462.

2. Cournand, A., Lauson, H. D., Bloomfield, R. A., Breed, E. S., and Baldwin, E. de F., Recording of right heart pressures in man. Proc. Soc. Exper. Biol. \& Med., 1944, 55, 34.

3. Cournand, A., Riley, R. L., Breed, E. S., Baldwin, E. de F., and Richards, D. W., Jr., Measurement of cardiac output in man using the technique of catheterization of the right auricle or ventricle. J. Clin. Invest., 1945, 24, 106.

4. Bloomfield, R. A., Lauson, H. D., Cournand, A., Breed, E. S., and Richards, D. W., Jr., Recording of right heart pressures in normal subjects and in patients with chronic pulmonary disease and various types of cardio-circulatory disease. J. Clin. Invest., 1946, 25, 639.

5. Aperia, A., Hemodynamical studies. Skandinav. Arch. f. Physiol., 1940, Supplement 16 (to 83), 1.

6. Meyer, H. H., und Gottlieb, R., Experimentelle Pharmakologie. Urban und Schwarzenberg, BerlinWien, 1936, p. 335, Ed. 9.

7. Gefter, W. I., and Leaman, W. G., Jr., Use of ouabain in rapid cardiac arrhythmias. Am. J. M. Sc., 1943, 205, 190.

8. Eichna, L. W., and Taube, H., Comparison of actions of 4 cardiac glycosides on a patient with congestive heart failure. Am. Heart J., 1943, 26, 631.

9. Eichna, L. W., and Taube, H., Effect of intravenously administered digoxin and ouabain on systemic venous pressure of patients with congestive heart failure. Am. Heart J., 1944, 27, 641.

10. Freedberg, A. S., and Zoll, P. M., Medical progress, digitalis. New England J. Med., 1946, 235, 938.

11. Movitt, E. R., Digitalis and Other Cardiotonic Drugs. Oxford University Press, New York, 1946.

12. Chavez, I., Comparative value of digitalis and of ouabain in the treatment of heart failure. Arch. Int. Med., 1943, 72, 168.

13. Richards, D. W., Jr., Cardiac output by the catheterization technique in various clinical conditions. Federation Proc., 1945, 4, 215.

14. Howarth, S., McMichael, J., and Sharpey-Schafer, E. P., Effects of oxygen, venesection and digitalis in chronic heart failure from disease of the lungs. Clin. Sci., 1947, 6, 187.

15. Cournand, A., Measurement of the cardiac output in man using the right heart catheterization. Federation Proc., 1945, 4, 207.

16. Richards, D. W., Jr., Cournand, A., Darling, R. C., and Gillespie, W. H., Pressure in the right auricle of man, in normal subjects and in patients with congestive heart failure. Tr. A. Am. Physicians, 1941, 56, 218.

17. Richards, D. W., Jr., Cournand, A., Darling, R. C., Gillespie, W. H., and Baldwin, E. de F., Pressure of blood in the right auricle, in animals and in man, under normal conditions and in right heart failure. Am. J. Physiol., 1942, 136, 115.

18. McMichael, J., and Sharpey-Schafer, E. P., The action of intravenous digoxin in man. Quart. $\mathrm{J}$. Med., 1944, 13, 123. 